\title{
CYTOTOXIC LABDANE DITERPENOIDS FROM ANDROGRAPHIS PANICULATA (BURM.F.) NEES
}

\author{
MARIA CARMEN S TAN ${ }^{1}$, GLENN G OYONG ${ }^{2,3}$, CHIEN-CHANG SHEN $^{4}$, CONSOLACION Y RAGASA ${ }^{1,5 *}$
}

apepartment of Chemistry, De La Salle University, 2401 Taft Avenue, Manila 1004, Philippines. ${ }^{2}$ Department of Biology, De La Salle University, 2401 Taft Avenue, Manila 1004, Philippines. ${ }^{3}$ Division of Chinese Medicinal Chemistry, Center for Natural Science and Environmental Research, De la Salle University, 2401 Taft Avenue, Manila 1004, Philippines. ${ }^{4}$ National Research Institute of Chinese Medicine, Ministry of Health and Welfare, 155-1, Li-Nong St., Section 2, Taipei, Taiwan. ${ }^{5}$ Department of Chemistry, De La Salle University Science and Technology Complex Leandro V. Locsin Campus, Biñan City, Laguna 4024, Philippines. Email: consolacion.ragasa@dlsu.edu.ph

Received: 15 April 2017, Revised and Accepted: 16 August 2017

ABSTRACT

Objective: The primary objective of this study was to probe the cytotoxic capacity of the labdane diterpenoids andrographolide (1), 14-deoxyandrographolide (2), 14-deoxy-12-hydroxyandrographolide (3), and neoandrographolide (4) on mutant and wild-type immortalized cell lines.

Methods: Breast adenocarcinoma (MCF-7), colon carcinomas (HCT-116 and HT-29), small cell lung carcinoma (H69PR), human acute monocytic leukemia (THP-1), and wild-type primary normal human dermal fibroblasts - neonatal cells (HDFn) were incubated with 1-4, and the degree of cytotoxicity was analyzed by employing the in vitro PrestoBlue $®$ cell viability assay. Working solutions of 1-4 were prepared in complete cell culture medium to a final non-toxic dimethyl sulfoxide concentration of $0.2 \%$. The plates were incubated at $37^{\circ} \mathrm{C}$ with $5 \% \mathrm{CO}_{2}$ in a $98 \%$ humidified incubator throughout the assay. Nonlinear regression and statistical analyses were done to extrapolate the half maximal inhibitory concentration $50 \%\left(\mathrm{IC}_{50}\right.$ ). One-way ANOVA $(\mathrm{p}<0.05)$ and multiple comparison, Tukey's post hoc test $(\mathrm{p}<0.05)$, were used to compare different pairs of data sets. Results were considered statistically significant at $\mathrm{p}<0.05$.

Results: The highest cytotoxicity index was exhibited by the H69PR and 1 trials which displayed the lowest $\mathrm{IC}_{50}$ value of $3.66 \mu \mathrm{g} / \mathrm{mL}$, followed by HT-29 treated with 2, HCT-116 and 1 trials, and H69PR treated with $4\left(\mathrm{IC}_{50}=3.81,3.82\right.$, and $4.19 \mu \mathrm{g} / \mathrm{mL}$, respectively). Only 1 and 4 were detrimental toward MCF-7, while 1, 3, and 4 were degenerative against H69PR. Tukey's post hoc multiple comparison indicated no significant difference in the cytotoxicity of 1-4 on HCT-116 cells which afforded $\mathrm{IC}_{50}$ values ranging from 3.82 to $5.12 \mu \mathrm{g} / \mathrm{mL}$. Evaluation of the two colon carcinoma cell lines showed that HCT-116 was categorically more susceptible to cellular damage caused by treatments with 1-4 than was HT-29. Cytotoxicity was not detected in THP-1 and HDFn cells $\left(\mathrm{IC}_{50}>100 \mu \mathrm{g} / \mathrm{mL}\right)$.

Conclusion: Diterpenoids 1-4 isolated from the dichloromethane extract of the leaves of A. paniculata exhibited different cytotoxic activities against MCF-7, HCT-116, HT-29, and H69PR. All constituents had comparable action on HCT-116 cells but were not found to be cytotoxic to normal HDFn cells and mutant THP-1 cells.

Keywords: Andrographis paniculata, Andrographolide, 14-deoxyandrographolide, Neoandrographolide, Cytotoxicity.

(c) 2017 The Authors. Published by Innovare Academic Sciences Pvt Ltd. This is an open access article under the CC BY license (http://creativecommons. org/licenses/by/4. 0/) DOI: http://dx.doi.org/10.22159/ajpcr.2017.v10i12.19194

\section{INTRODUCTION}

There has been an upsurge in cancer diagnosis and death worldwide. The root cause of this phenomena is linked to a longer lifespan and an incorporation of inappropriate activities such as smoking, physically inactive lifestyles, and unhealthy diets, especially in economically emerging nations. GLOBOCAN 2008 reported that there were 12.7 million patients diagnosed with malignancies and 7.6 million mortalities associated with cancer which occurred in 2008. Statistical analyses stipulated that $56 \%$ of the pin-pointed patients and $64 \%$ of the deaths happened in developing countries [1]. Andrographis paniculata (Burm. f.) Nees, which belongs to the family Acanthaceae, has been found to have carcinopreventive and immunostimulatory constituents [2,3]. This herb, which is found locally in Taiwan, Mainland China, and India, leaves an acrimonious taste to the palate. It is used in traditional medicine for liver disorders, bowel discomfort of children or colic, and viral or bacterial upper respiratory tract infections [4-6]. Chinese medicine postulated that the aerial part of $A$. paniculata has the ability to decrease body temperature, reduce inflammation, and relieve aches. Concoctions of this plant have been linked with physiological detoxification or purging [7-9].

Steroids, alkaloids, flavonoids, triterpenoids, tannins, saponins, quinone, coumarin, protein, sugar, and gum were the constituents established to be present in A. paniculata [10]. Diterpenoids, flavonoids, and polyphenols have been found to be the chemotherapeutic agents of A. paniculata [11,12]. Pharmacokinetic interaction experiments propose that $A$. paniculata could cause the inhibition of UDPglucuronosyltransferase in drug metabolism [13]. The flavonoids isolated from the ethyl acetate fraction derived from ethanolic or methanolic extraction were reported to contain 5-hydroxy-7,8dimethoxyflavone, 5-hydroxy-7,8,2',5'-tetramethoxyflavone, 5-hydroxy7,8,2',3'-tetramethoxyflavone, 5-hydroxy-7,8,2'-trimethoxyflavone, 7-O-methylwogonin, and 2'-methyl ether [14-16]. The ethyl acetate fraction of $A$. paniculata in conjunction with doxorubicin considerably $(p<0.05)$ escalated programed cell death in mice fibrosarcoma cells and diminished vascular endothelial growth factor production $(\mathrm{p}<0.05)$ [17]. The primary diterpene of $A$. paniculata was stated to be rographolide and has been chronicled to constitute $4 \%, 0.8 \sim 1.2 \%$, and $0.5 \sim 6 \%$ in dried whole plant, stem, and leaf preparations, respectively [18-20]. Other prominent labdane diterpenoids were deoxyandrographolide, neoandrographolide, 14-deoxy-11,12-didehydroandrographide, and isoandrographolide [15,17].

Our previous investigation recounted the isolation of 14-deoxy-12hydroxyandrographolide, 14-deoxyandrographolide, and 14-deoxy11,12-dihydroandrographolide from the leaves of A. paniculata [21]. 
Recently, we reported the isolation of andrographolide, 14-deoxyandrographolide, 14-deoxy-12-hydroxyandrographolide, $\beta$-sitosterol, stigmasterol, and chlorophyll a from the leaves; $\beta$-sitosterol, stigmasterol, 5,2'-dihydroxy-7,8-dimethoxyflavone, long chain transcinnamate esters, and $\beta$-sitosteryl fatty acid esters from the roots; $\beta$-sitosterol, monogalactosyl diacylglycerols, lupeol, and triacylglycerols from the pods; and 14-deoxyandrographolide from the stems of A. paniculata [22]. We also reported the isolation of squalene, polyprenol, lutein, chlorophyll a, and a mixture of $\beta$-sitosterol and stigmasterol in a 3:1 ratio from the stems; and $\alpha$-amyrin acetate, triacylglycerols, and a mixture of lupeol, $\alpha$-amyrin, and $\beta$-amyrin in about 2:2:1 ratio from the leaves of $A$. paniculata [23]. Our most recent research from the dichloromethane extracts of the leaves of $A$. paniculata led to the isolation of neoandrographolide, 1,5-dimethyl-1,5-cyclooctadiene and 2-hydroxyethyl benzoate, and squalene from the leaves, while the stems yielded 1,5-dimethyl-1,5-cyclooctadiene [24]

In this work, the cytotoxic capabilities of andrographolide (1), 14-deoxyandrographolide (2), 14-deoxy-12-hydroxyandrographolide (3), and neoandrographolide (4) against the immortalized human cell lines, breast adenocarcinoma (MCF-7), colon cancer (HCT-116 and HT-29), small cell lung carcinoma (H69PR), and acute monocytic leukemia (THP-1) were established. To the best of our knowledge, this is the first reported study using this methodology of cytotoxic and anti-proliferative analyses on 1-4 from A. paniculata against the aforementioned human cancer cells as shown in following Fig. 1.

\section{METHODS}

\section{Sample collection}

The A. paniculata (Burm.f.) Nees leaves were grown and harvested in Abucay, Bataan, on September 2015. The sample was authenticated at the botany division of the Philippine National Museum.

\section{Isolation}

The labdane diterpenoids 1-3 [22] and 4 [23] were isolated from the leaves of $A$. paniculata. The isolation procedures were previously reported $[22,23]$.

\section{Preparation of compounds}

Compounds 1-4 from A. paniculata were reconstituted in dimethyl sulfoxide (DMSO) to formulate an initial solution of $4 \mathrm{mg} / \mathrm{mL}$. Dilutions were made from the stock solution using $0.2 \%$ DMSO and the appropriate cell culture medium.

\section{Maintenance and preparation of cells}

The dichloromethane $\left(\mathrm{CH}_{2} \mathrm{Cl}_{2}\right)$ extracts of $A$. paniculata were analyzed for their bioactivity on the following human cell lines purchased from ATCC, Manassas, Virginia, U.S.A.): Breast cancer (MCF-7), colon cancer (HCT-116 and HT- 29), small cell lung carcinoma (H69PR), human acute monocytic leukemia (THP-1); and a primary culture of normal human dermal fibroblast and neonatal (HDFn) (ThermoFisher Scientific, Gibco®, USA) which were stored at the Cell and Tissue Culture Laboratory, Molecular Science Unit, Center for Natural Science, and Environmental Research at De La Salle University. Standard protocols were strictly adhered to throughout the analyses [25]. Complete growth medium comprised of Dulbecco's Modified Eagle Medium (DMEM, ThermoFisher Scientific Gibco $\AA$, USA), having $10 \%$ fetal bovine serum (FBS, ThermoFisher Scientific, Gibco®, USA), and 1x antibiotic-antimycotic (ThermoFisher Scientific, Gibco $®$, USA) was used in the plate cultures. To maintain the environment of the cell cultures, the plates were placed in a humidified incubator at $37^{\circ} \mathrm{C}$ with $5 \% \mathrm{CO}_{2}$ in $98 \%$ humidity. The monolayer adherent cells, after attainment of $80 \%$ confluence, were rinsed with phosphatebuffered saline (PBS, pH 7.4, ThermoFisher Scientific, Gibco®, USA), trypsinized with $0.05 \%$ Trypsin-EDTA (ThermoFisher Scientific, Gibco ${ }^{\circledR}$, USA) and reconstituted with freshly prepared media. Cells were counted following a standard trypan blue exclusion method (0.4\% Trypan Blue Solution from ThermoFisher Scientific, Gibco®, USA). Seeding of the $96-$ well microtiter plate (Falcon ${ }^{\mathrm{TM}}$, USA) in $100 \mu \mathrm{L}$ portions was calculated to have $1 \times 10^{4}$ cells per well. Cell viability was found to be greatly affected by toxic agents at lower starting cell density or cell count, whereas higher optical densities of cells readily bound and rendered unavailable the added agents [26]. Due to these reported incidences, the researchers chose this level of cell density to avoid any perturbations caused by unsuitable OD. To accomplish optimum cell attachment, additional incubation of the plates in a $37^{\circ} \mathrm{C}$ with $5 \% \mathrm{CO}_{2}$ in a $98 \%$ humidified environment was done overnight. The bioassays, as defined in the subsequent section, will be undertaken on the processed plates.

\section{Cell viability assay}

The degree of cytotoxicity of the A. paniculata compounds on the immortalized cell lines was established using PrestoBlue ${ }^{\circledR}$ (ThermoFisher Scientific, Molecular Probes ${ }^{\circledR}$, in vitro gen, USA) for cell viability analyses. The basis of the bioassay hinges on the measurement of the quantity of mitochondrial reductase in intact cells which metabolically alters resazurin dye (blue and nonfluorescent) to resorufin (red and highly fluorescent). The reaction is proportionate to the amount of metabolically viable cells which is quantified spectrophotometrically at absorbance measurements of $570 \mathrm{~nm}$. Aliquots of $100 \mu \mathrm{L}$ of filter purified 1-4 were first applied to the cells in the microtiter plate. Subsequent two-fold serial dilutions of 50, 25, $12.5,6.25,3.12,1.56,0.78$, and $0.39 \mu \mathrm{g} / \mathrm{mL}$ were done after the first treatment on each trial. The plates were then subjected to an incubation period of 4 days at $37^{\circ} \mathrm{C}$ in $5 \% \mathrm{CO}_{2}$ and $98 \%$ humidity. PrestoBlue $®$ (twenty microliters) was administered to each well. Another incubation period for $1 \mathrm{hr}$ at $37^{\circ} \mathrm{C}$ in $5 \% \mathrm{CO}_{2}$ and $98 \%$ humidity was employed to the monolayers. Negative controls were the wells which were not treated with any of the samples, and the positive control was the wells treated with the cytotoxic agent Zeocin ${ }^{\mathrm{TM}}$ (ThermoFisher Scientific, Gibco®, USA). Spectrophotometric analyses were performed using a BioTek ELx800 Absorbance Microplate Reader (BioTek® Instruments, Inc., USA) at $570 \mathrm{~nm}$ and normalized to $600 \mathrm{~nm}$ values (reference wavelength). Cell viability for each sample concentration was evaluated following the equation below.

\section{Cell viability $\%=$}

(Absorbance of treated sample-absorbance of blank) (Absorbance of negative control-absorbance of blank)

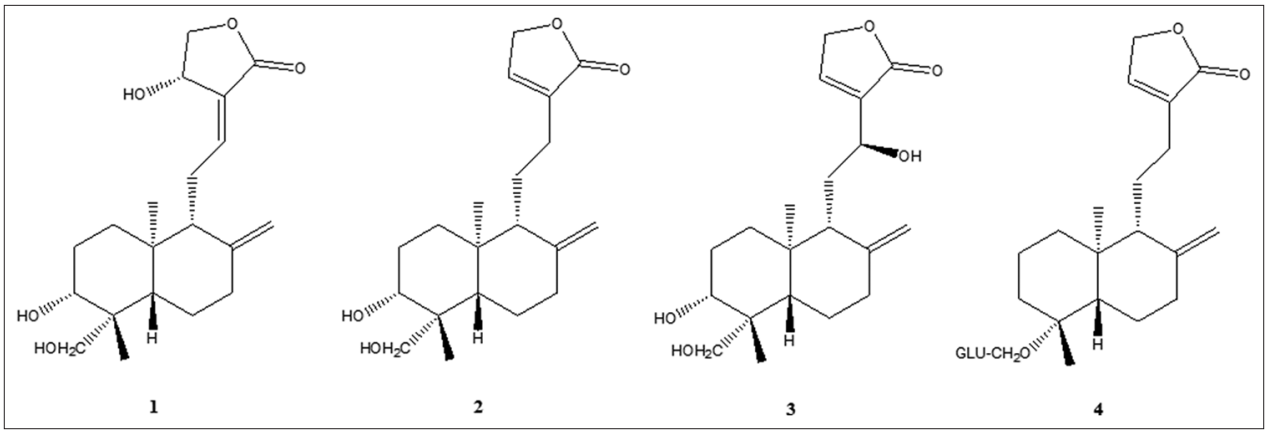

Fig. 1: Chemical structures of 1-4 
GraphPad Prism 7.01 (GraphPad Software, Inc.) was employed to compute for nonlinear regression and the half maximal inhibitory concentration $50 \%\left(\mathrm{IC}_{50}\right.$ ) (the concentration of the constituent which caused a $50 \%$ decline in cell viability). The extent of cytotoxicity of 1-4 was stated as $\mathrm{IC}_{50}$ values. Every trial was executed in triplicate and the data displayed as mean \pm standard deviation error. Evaluation of the variances in the best-fit parameters (half maximal inhibitory concentration) between treatments and regularities among doseresponse curve fits was verified using the extra sum-of-squares F-test or Brown-Forsythe test. Significant variances among data sets were ascertained through one-way ANOVA $(\mathrm{p}<0.05)$ followed by Tukey's post hoc test $(\mathrm{p}<0.05)$ for multiple comparisons. Results were deliberated to be statistically significant at $\mathrm{p}<0.05$.

\section{RESULTS AND DISCUSSION}

The cytotoxicity of andrographolide (1), 14-deoxyandrographolide (2), 14-deoxy-12-hydroxyandrographolide (3), and neoandrographolide (4) were investigated on MCF-7, HT-29, HCT-116, H69PR, THP-1, and HDFn. Analyses of the cytotoxicity of 1-4 against THP- 1 resulted to $\mathrm{IC}_{50}$ values exceeding $100 \mu \mathrm{g} / \mathrm{mL}$, suggesting absence of cytotoxic activities, and were excluded from further statistical analysis. Zeocin, an intercalating agent, was used as the positive control in all the trials. An illustration of the percent cell viability as a function of the logarithmic function of the concentrations used is presented in Figs. 2 and 3. The characteristic inhibitory dose response, which is a sigmoidal curve or function, was found in generally most of the charts. Plots comparing the cytotoxic properties of 1-4 on the viability of each specific cell line are found in Fig. 2. The effects of each individual constituent on all the cell lines are shown in Fig. 3. $\mathrm{IC}_{50}$ values of the isolates and the positive control are synopsized in Table 1.

Within the MCF-7 subset, 1 demonstrated considerable activity toward breast adenocarcinoma as exhibited by the $\mathrm{IC}_{50}$ value of $4.21 \mu \mathrm{g} / \mathrm{mL}$, followed by the activity of 4 with an $\mathrm{IC}_{50}$ value of $6.63 \mu \mathrm{g} / \mathrm{mL}$. No cytotoxicity was displayed by 2 and 3 since the $\mathrm{IC}_{50}$ values were greater than $100 \mu \mathrm{g} / \mathrm{mL}$. No significant differences, as found in Tukey's post hoc multiple comparison, were found between 1 versus 4, 1 versus Zeocin, and 4 versus Zeocin ( $>0.05)$, while all the other paired treatments were found to be significantly different $(\mathrm{p}<0.0001)$.
Compounds 1-4 exhibited marked degradative properties on HCT-116 with 1 being the most damaging at an $\mathrm{IC}_{50}$ value of $3.82 \mu \mathrm{g} / \mathrm{mL}$ and 4 , 3 , and 2 following suit with $\mathrm{IC}_{50}$ values of $4.43,4.82$, and $5.12 \mu \mathrm{g} / \mathrm{mL}$, respectively. Post hoc analysis exhibited no significant differences between the paired treatments ( $\mathrm{p}>0.05)$.

HT-29 was most vulnerable to 2 with an $\mathrm{IC}_{50}$ value of $3.81 \mu \mathrm{g} / \mathrm{mL}$. Impediment of the viability of HT-29 cells on 1, 3, and 4 was only established at elevated concentrations, as evidenced by the $\mathrm{IC}_{50}$ values of $69.19 \mu \mathrm{g} / \mathrm{mL}$ for $3,83.03 \mu \mathrm{g} / \mathrm{mL}$ for 4 and $>100 \mu \mathrm{g} / \mathrm{mL}$ for 1 . The $\mathrm{IC}_{50}$ data of the subsets 1 versus 2, 2 versus 3, 2 versus 4,1 versus zeocin, 3 versus Zeocin, and 4 versus Zeocin were statistically different $(\mathrm{p}<0.0001)$, while the remaining paired treatments were similar $(\mathrm{p}>0.05)$.

Diterpenoid 1 gave the highest efficacy toward H69PR with a half maximal inhibitory concentration of $3.66 \mu \mathrm{g} / \mathrm{mL}$, which was followed by 4 and 3 which gave IC $_{50}$ values of 4.19 and $4.86 \mu \mathrm{g} / \mathrm{mL}$, respectively. Compound 2 was non-cytotoxic and was only able to decrease cell viability by $50 \%$ at $\mathrm{IC}_{50}>100 \mu \mathrm{g} / \mathrm{mL}$. Statistical paired treatments

Table 1: Cytotoxic activities (IC I0 $_{50}$ of 1-4 and Zeocin against MCF-7, HCT-116, HT-29, H69PR, and HDFn

\begin{tabular}{|c|c|c|c|c|c|}
\hline \multirow[t]{2}{*}{ Compound } & \multicolumn{5}{|c|}{$\mathrm{IC}_{50} *(\mu \mathrm{g} / \mathrm{mL})$} \\
\hline & MCF-7 & HCT-116 & HT-29 & H69PR & HDFn \\
\hline 1 & 4.21 & 3.82 & $>100$ & 3.66 & $>100$ \\
\hline 2 & $>100$ & 5.12 & 3.81 & $>100$ & $>100$ \\
\hline 3 & $>100$ & 4.82 & 69.19 & 4.86 & $>100$ \\
\hline 4 & 6.63 & 4.43 & 83.03 & 4.19 & $>100$ \\
\hline Zeocin & 3.70 & 4.25 & 3.50 & 4.82 & 3.76 \\
\hline
\end{tabular}

${ }^{*} \mathrm{IC}_{50}$ values were extrapolated from dose-response curves calculated from nonlinear regression analysis using GraphPad Prism 7.01 (GraphPad Software, Inc.) and one-way ANOVA was the treatment employed for each cell line to evaluate the significant variances among the data groups. The statistical analyses are as follows: MCF-7, F $(4,35)=11.31$, p <0.0001; HCT-116, $\mathrm{F}(4,35)=0.07427, \mathrm{p}=0.9895$; HT-29, $\mathrm{F}(4,35)=5.661, \mathrm{p}=0.0013$; H69PR, $\mathrm{F}(4,35)=1.38, \mathrm{p}=0.2609$; HDFn, $\mathrm{F}(4,35)=15.62$, p $<0.0001$. IC $_{50}$ : Inhibitory concentration $50 \%$, HDFn: Human dermal fibroblasts - neonatal cells

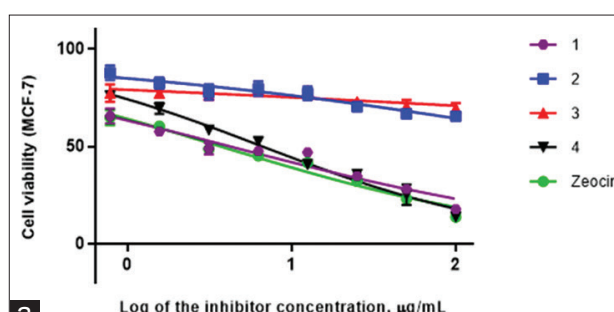

a

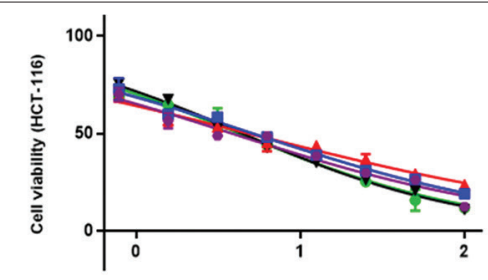

b

Log of the inhibitor concentration, $\mu \mathrm{g} / \mathrm{mL}$

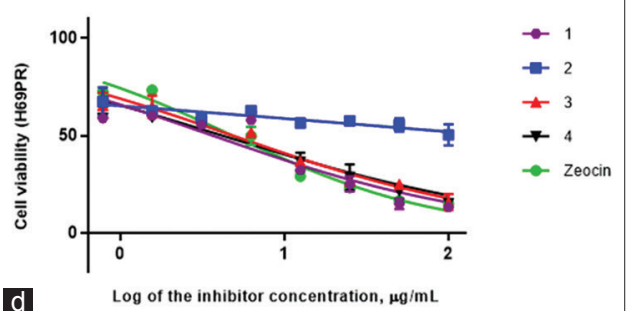

Fig. 2: Dose-response curves showing the cytotoxic activities of 1-4 and Zeocin on the cell viability of MCF-7, HCT-116, HT-29, and H69PR: Each plot displays the effect of 1-4 and Zeocin against each cell line. Data are shown as mean \pm standard deviation error. GraphPad Prism 7.01 was used to perform extra sum-of-squares F-test to (a) evaluate the significance of the best-fit-parameter (half maximal inhibitory concentration) among different treatments and to (b) determine the differences among the dose-response curve fits. The results are: MCF-

7, (a) F $(4,110)=464.7$, p $<0.0001$; (b) F $(4,35)=3.926$, $p=0.0098$, HCT-116; (a) F $(4,110)=2.861$, $p=0.0267$; (b) F $(4,35)=0.604$, p=0.6623;

HT-29, (a) F $(4,110)=155,2$, p $<0.0001$; (b) F $(4,35)=1.364$, p=0.2662, H69PR; (a) F $(4,110)=20.37$, $p<0.0001$; (b) $F(4,35)=6.688$, $p=0.0004$; human dermal fibroblasts - neonatal cells; (a) F $(4,95)=160.1, p<0.0001$; (b) $F(4,32)=2.572, p=0.0566$ 


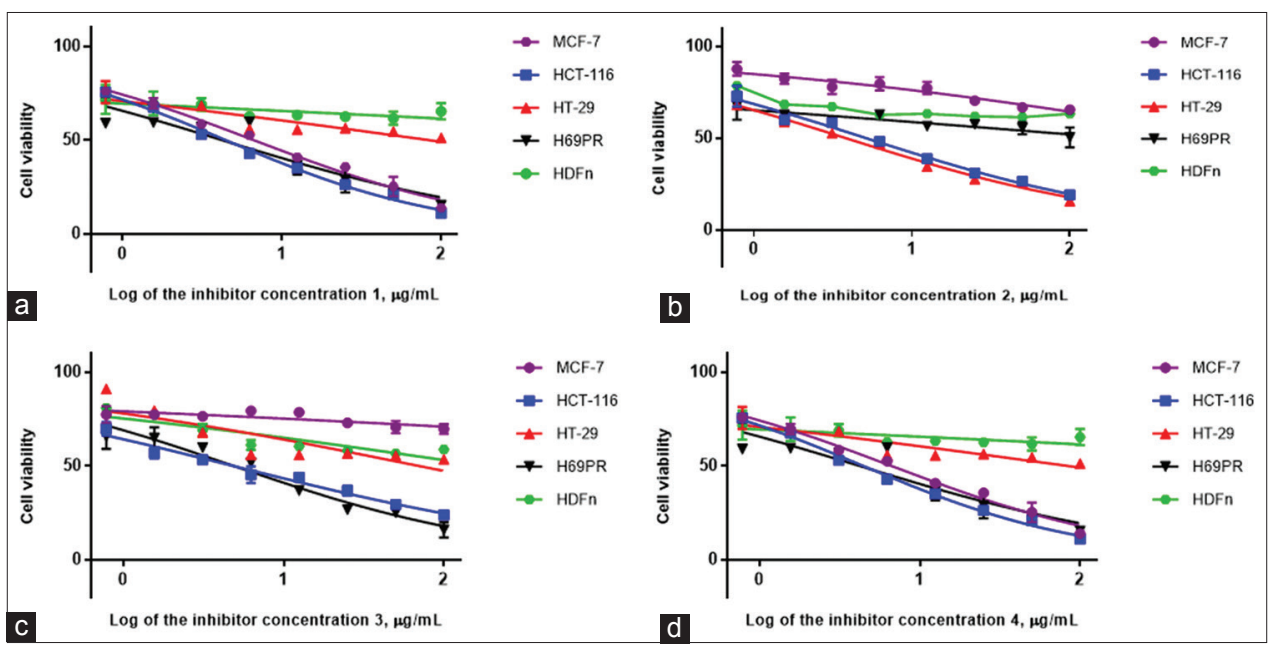

Fig. 3: Dose-response curves showing the cytotoxic activities of 1-4 and Zeocin on the cell viability of MCF-7, HCT-116, HT-29, H69PR, and human dermal fibroblasts - neonatal cells: Each plot displays the effect of 1-4 and Zeocin against each cell line. Data are shown as mean \pm standard deviation error. GraphPad Prism 7.01 was used to perform extra sum-of-squares F-test to (a) evaluate the significance of the best-fit-parameter (half maximal inhibitory concentration) among different treatments, and to (b) determine the differences among the dose-response curve fits. The results are: 1 , (a) $F(4,110)=92.64$, $p<0.0001$; (b) $F(4,35)=3.221, p=0.0237,2$; (a) $F(4,104)=409.6$,

$\mathrm{p}<0.0001$; (b) $\mathrm{F}(4,33)=6.767$, p=0.0004, 3; (a) $\mathrm{F}(4,110)=164.5$, $\mathrm{p}<0.0001$; (b) $\mathrm{F}(4,35)=8.636, \mathrm{p}<0.0001,4$; (a) $\mathrm{F}(4,110)=125.4$, p $<0.0001$; (b) $F(4,35)=5.32$, p=0.0019, Zeocin; (a) $F(4,110)=3.356, p=0.0124 ;$ (b) $F(4,35)=0.8901, p=0.4801$

between pairs displayed that 1 versus 3, 1 versus 4,3 versus 4,1 versus Zeocin, 3 versus Zeocin, and 4 versus Zeocin were not statistically different ( $p>0.05)$, while the other treatments were distinctly diverse $(\mathrm{p}<0.0001)$.

All the isolates were established not to be cytotoxic to wild-type HDFn, with $\mathrm{IC}_{50}$ values substantially surpassing concentrations of $100 \mu \mathrm{g} /$ $\mathrm{mL}$. Compounds 1 versus 4, 3 versus 4, 3 versus Zeocin, and 4 versus Zeocin were found to be significantly disparate $(\mathrm{p}<0.006)$. Zeocin a known cytotoxic agent gave $\mathrm{IC}_{50}$ values of $3.70,4.25,3.50,4.82$, and $3.76 \mu \mathrm{g} / \mathrm{mL}$ for MCF-7, HCT-116, HT-29, H69PR, and HDFn, respectively, and multiple comparisons showed no significant difference among the trials ( $p>0.05)$. Post-hoc comparison of the dose-response curve fits for most of the cell line treatments exhibited significant differences, with the exception of the analyses of HCT-116 trials with 1-4 which were not statistically different ( $p>0.05$ ) (Figs. 1 and 2).

Assessment of the effectiveness of 1-4 on the four immortalized cancer cell lines revealed that the integrity of HCT-116 cells consistently decreased in all the trials, and the action of cytotoxicity was analogous to the positive control Zeocin. For the most part, H69PR cells also followed this trend of degeneration with the exception of 2 , and in HT-29, high half maximal inhibitory concentrations were acquired for most of the trials, with the exception of 1 . On the other hand, only 1 and 4 were cytotoxic to MCF-7. With regard to the efficacy of each compound, 1 was most effective toward H69PR, HCT-116, and MCF-7, with $\mathrm{IC}_{50}$ values of $3.66,3.82$, and $4.21 \mu \mathrm{g} / \mathrm{mL}$, respectively. Labdane diterpenoid 2 was most effectual against HCT-116 and HT-29 with $\mathrm{IC}_{50}$ values of 5.12 and $3.81 \mu \mathrm{g} / \mathrm{mL}$, correspondingly. Compound 3 was also found to be a degenerative agent toward HCT-116 and HT-29; however, HT-29 was only damaged at a higher concentration of $69.19 \mu \mathrm{g} / \mathrm{mL}$. In addition, 3 was detrimental to H69PR at an $\mathrm{IC}_{50}$ value of $4.86 \mu \mathrm{g} / \mathrm{mL}$. Diterpenoid glucoside 4 exhibited highest efficacy toward H69PR $\left(\mathrm{IC}_{50}=4.19 \mu \mathrm{g} / \mathrm{mL}\right.$ ), followed by the cell lines HCT-116 (IC I0 $\left._{50}=4.43 \mu \mathrm{g} / \mathrm{mL}\right)$ and MCF-7 (IC $\left.{ }_{50}=6.63 \mu \mathrm{g} / \mathrm{mL}\right)$, and was non-cytotoxic to HT-29 $\left(\mathrm{IC}_{50}=83.03 \mu \mathrm{g} / \mathrm{mL}\right)$. Wild-type HDFn gave half maximal inhibitory concentrations of greater than $100 \mu \mathrm{g} / \mathrm{mL}$ in all of the trials.

The stipulated active cytotoxic limits of natural products are $20 \mu \mathrm{g} / \mathrm{mL}$ or less for crude extracts and $4 \mu \mathrm{g} / \mathrm{mL}$ or less for pure compounds [27], and constituents that have been purified which exhibit promising cytotoxicity levels are possible proponents for drug development [28]. The findings in this work disclosed that 1-4 from A. paniculata can be candidates for chemotherapeutic drugs or used as a corollary for medical protocols in dealing with the management of human colon and colorectal cancer, human breast adenocarcinoma, and human small cell lung carcinoma.

This research displayed that the cytotoxicity of 1-4 was reliant on the particular immortalized cancer cell line used. Comparison of the two colon carcinomas showed that HCT-116 was more responsive to all the compounds, especially to 1 , and HT-29 was highly deteriorated by 2 and marginally affected by 3 and 4 . This disparity can be explained by tumor heterogeneity which can exhibit variance in drug-related response due to the modification and differences in HCT-116 and HT-29 expression profiles [29]. Transformations on the gene sequence such as in the mutant form of the $p 53$ gene in HT-29 has made this type of colorectal cancer more resilient to the cytotoxic action of doxorubicin than the HCT-116 cell line, carrying a normal-type p53 gene [30].

Literature search on the cytotoxic and chemotherapeutic activity of the diterpenes in A. paniculata has been conducted; however, to the best of our knowledge, no reported activities on1-4 using these cell lines and these parameters have been cited.

Andrographolide's anticancer pharmacognosy has been linked to its ability to subdue tumor growth, instigation of apoptosis, prevention of angiogenesis, and the hindrance of the neoplasm's anti-transformative capacity [31]. Andrographolide (1) was found to promote DNA fragmentation at concentrations of $0.35 \mathrm{mM}, 0.70 \mathrm{mM}$, and $1.40 \mathrm{mM}$. The accelerated accumulation of apoptotic cells was observed when TD-47 human breast cancer cells were incubated with andrographolide for 24, 48, and $72 \mathrm{hrs}$. The onset of apoptosis in TD-47 and human breast cancer cell line was determined to be subject to the length of time of the treatment and the concentration of the constituent. The mechanism of apoptosis was proposed to be due to the upregulation of p53, bax, and caspase- 3 and down-regulation of bcl-2 as analyzed through immunohistochemical analysis [32]. Using a dual-luciferase reporter assay, it was found that HIF-1 in T47D cells at EC50 of $1.03 \times 10^{-7} \mathrm{~mol} / \mathrm{L}$ led to the decrease of vascular endothelial growth factor (VEGF) [33]. The decline of the proliferation of the mutant cells from human breasts, MDA-MB-231, was attributed to the rise in reactive oxygen species which occurs concurrently with the loss in mitochondrial membrane 
potential and externalization of phosphatidylserine [34]. Compound 1 has been implicated in the stimulation of heme oxygenase- 1 (HO- 1 ) expression which has been found to moderately contribute to the inhibition of TPA-induced matrix metalloproteinase-9 (MMP-9) and MCF-7 cells motility [35]. A comparable inhibitory influence of 1 on HT-29 was observed by the encumbrance of the migration of colon carcinoma through the inhibition of MMP-2 [31]. The combination of 1 with cisplatin (CDDP) induced a synergistic inhibition on the growth of human colorectal carcinoma lovo cells and was found to initiate apoptosis in vitro [36]. Andrographolide normalized VEGF and TGF- $\beta 1$ levels and constrained protein kinase C in H3255 cells which contributed to a decrease in the proliferation of lung cancer cells in a concentration-dependent assay [37]. In A549 cells, 1 was established to facilitate continued downregulation of phosphatidylinositol 3-kinase (PI3K)/Akt signal which was involved in the gene expression of MMPs in reaction to activator protein-1 (AP-1) [38]. Therefore, previously reported signaling pathways and mechanisms involved verifies our results that 1 has notable cytotoxicity at an $\mathrm{IC}_{50}$ value $4.21 \mu \mathrm{g} / \mathrm{mL}$ and can be considered as a bioactive agent against breast adenocarcinoma cell line MCF-7 with low cytotoxicity to wild-type $\mathrm{HDFn}\left(\mathrm{IC}_{50}>100 \mu \mathrm{g} / \mathrm{mL}\right)$.

The chemotherapeutic pathways mediated by andrographolide treatment involve the inhibition of Janus tyrosine kinases-signal transducers and activators of transcription, $\mathrm{PI} 3 \mathrm{~K}$, and NF- $\mathrm{KB}$ signaling pathways, suppression of heat shock protein 90 , cyclins and cyclindependent kinases, metalloproteinase and growth factors, and the induction of proteins p53 and p21, leading to the disablement of aberrant cell viability, tumor - cell invasion/migration, and growth in the vascular network [39].

After incubation with 14-deoxyandrographolide (2), amplified microsomal Ca-ATPase action due to the instigation of the NO/cGMP conduit was observed. This resulted in the inhibition of a deathinducing signaling complex (TNFRSF1A-ARTS-1-NUCB2) in cellular compartments, rendering the hepatocytes incapable of TNF- $\alpha$ induced cell death[40]. An earlier research has revealed that 2 acts as an immunomodulatory and anti-atherosclerotic agent [31]. Chemotherapeutic and anti-cancer properties of specific agents possess inherent selective growth inhibition or cytotoxic properties [41].

On the other hand, 14-deoxy-12-hydroxyandrographolide (3) was reported to be cytotoxic to human lung carcinoma (A549) with an IC $_{50}$ value of $20 \mu \mathrm{g} / \mathrm{mL}$ and manifested minimal antimicrobial response [21].

Neoandrographolide (4) was found to act as a chemosensitizer in S-Jurkat and X chromosome-linked deterrence of apoptosis protein (XIAP)-overexpressing Jurkat cells [42]. Andrographolide, 14-deoxyandrographolide, and neoandrographolide were isolated from chloroform and methanolic extracts of A. paniculata. Among these compounds, 4 possessed cytotoxic activity against cancer cell lines Hep G2 and HCT-116 as assessed by the MTT Assay. Evidence of apoptosis or necrosis was analyzed using DAPI, and acridine orange displayed DNA fragmentations which confirmed that cell death occurred due to the apoptotic pathway [43].

The structure-activity relationships of synthesized 1 analogs as novel cytotoxic agents disclosed that the intact $\alpha$-alkylidene $\gamma$-butyrolactone moiety of 1, the D12(13) double bond, the C-14 hydroxyl or its ester moiety, and the D8(17) double bond or epoxy moiety were responsible for the degenerative activities induced by 1 and its derivatives [44]. The presence of these functionalities within 1-4 could be the explanation of the cytotoxic action observed in the MCF-7, HCT-116, HT-29, and H69PR immortalized cell lines.

\section{CONCLUSION}

The labdane diterpenoids and andrographolide (1), 14-deoxyandrographolide (2), 14-deoxy-12-hydroxyandrographolide (3), and neoandrographolide(4) isolated from the dichloromethane extract of the leaves of A. paniculata exhibited different cytotoxic activities against MCF-7, HCT-116, HT-29, and H69PR, respectively. The comparison of the cytotoxic activity of 1-4 was highest for H69PR with an IC $\mathrm{I}_{50}$ value of $3.66 \mu \mathrm{g} / \mathrm{mL}$ for 1 , followed by HT-29 with an $\mathrm{IC}_{50}$ value of $3.81 \mu \mathrm{g} / \mathrm{mL}$ for 2 , HCT-116 with an IC $_{50}$ value of $3.82 \mu \mathrm{g} / \mathrm{mL}$ for $1, \mathrm{H} 69 \mathrm{PR}$ with an $\mathrm{IC}_{50}$ value of $4.19 \mu \mathrm{g} / \mathrm{mL}$ for 4 , and MCF-7 with an $\mathrm{IC}_{50}$ value of $4.21 \mu \mathrm{g} / \mathrm{mL}$ for 1 . Diterpenoid 3 was found to be most degenerative to HCT-116 with an $\mathrm{IC}_{50}$ value of $4.82 \mu \mathrm{g} / \mathrm{mL}$. Isolates 1-4 displayed substantial antiproliferative action on the human colon carcinoma immortalized cell line, HCT-116. Post hoc multiple analyses exhibited no significant difference in the dose-response curve fits of the cytotoxicity of 1-4 on HCT-116 cells with $\mathrm{IC}_{50}$ values ranging from 3.82 to $5.12 \mu \mathrm{g} / \mathrm{mL}$. All compounds were not found to be cytotoxic to normal HDFn cells and mutant THP- 1 cells with IC $_{50}$ values of $>100 \mu \mathrm{g} / \mathrm{mL}$.

\section{ACKNOWLEDGMENT}

A research grant from De La Salle University Science Foundation, through the University Research Coordination Office, is gratefully acknowledged.

\section{REFERENCES}

1. Jemal A, Bray F, Center MM, Ferlay J, Ward E, Forman D. Global cancer statistics. CA Cancer J Clin 2011;61(2):69-90.

2. Kumar RA, Sridevi K, Kumar NV, Nanduri S, Rajagopal S. Anticancer and immunostimulatory compounds from Andrographis paniculata. J Ethnopharmacol 2004;92(2-3):291-5.

3. Awan AJ, Ahmed CB, Uzair M, Aslam MS, Farooq U, Ishfaq K. Family Acanthaceae and Genus Aphelandra: Ethnopharmacological and phytochemical review. Int J Pharm Pharm Sci 2014;6(10):44-50.

4. Negi AS, Kumar JK, Luqman S, Shanker K, Gupta MM, Khanuja SP. Recent advances in plant hepatoprotectives: A chemical and biological profile of some important leads. Med Res Rev 2008;28(5):746-72.

5. Roxas M, Jurenka J. Colds and influenza: A review of diagnosis and conventional, botanical, and nutritional considerations. Altern Med Rev 2007;12(1):25-48.

6. Kligler B, Ulbricht C, Basch E, Kirkwood CD, Abrams TR, Miranda M, et al. Andrographis paniculata for the treatment of upper respiratory infection: A systematic review by the natural standard research collaboration. Explore 2006;2:25-9.

7. Huang CJ, Wu MC. Differential effects of foods traditionally regarded as 'heating' and 'cooling' on prostaglandin $\mathrm{E}_{2}$ production by a macrophage cell line. J Biomed Sci 2002;9:596-606.

8. Chao WW, Kuo YH, Li WC, Lin BF. The production of nitric oxide and prostaglandin E2 in peritoneal macrophages is inhibited by Andrographis paniculata, Angelica sinensis and Morus alba ethyl acetate fractions. J Ethnopharmacol 2009;122(1):68-75.

9. Mandal SC, Dhara AK, Maiti BC. Studies on psychopharmacological activity of Andrographis paniculata extract. Phytother Res 2001;15(3):253-6.

10. Salna KP, Sreejith K, Uthiralingam M, Prince MA, Milton J, Fleming AT. A comparative study of phytochemicals investigation of Andrographis paniculata and Murraya koenigii. Int J Pharm Pharm Sci 2011;3(3):291-2

11. Rao YK, Vimalamma G, Rao CV, Tzeng Y. Flavonoids and andrographolides from Andrographis paniculata. Phytochemestry 2004;65:2317-21.

12. Xu C, Chou GX, Wang ZT. A new diterpene from the leaves of Andrographis paniculata Nees. Fitoterapia 2010;81(6):610-3.

13. Abidin SZ, Liew WL, Ismail S, Chan KL, Mahmud R. Inhibitory effects of active constituents and extracts of Andrographis paniculata on Ugt1a1, Ugt1a4, and Ugt2b7 enzyme activities. Int J Pharm Pharm Sci 2014;6(6):58-66.

14. Kishore PH, Reddy MV, Reddy MK, Gunasekar D, Caux C, Bodo B. Flavonoids from Andrographis lineata. Phytochemistry 2003;63(4):457-61.

15. Bhaskar Reddy MV, Kishore PH, Rao CV, Gunasekar D, Caux C, Bodo B. New 2'-oxygenated flavonoids from Andrographis affinis. J Nat Prod 2003;66(2):295-7.

16. Kuroyanagi M, Sato M, Ueno A, Nishi K. Flavonoids from Andrographis paniculata. Chem Pharm Bull 1987;35:4429-35.

17. Sukardiman S, Suharjono, Balqianur T. The role of ethyl acetate fraction of Andrographis paniculata and doxorubin combination toward the increase of apoptosis and decrease of VEGF protein expression of mice fibrosarcoma cells. Int J Pharm Pharm Sci 2015;7(4):347-50.

18. Cheung HY, Cheung CS, Kong CK. Determination of bioactive 
diterpenoids from Andrographis paniculata by micellar electrokinetic chromatography. J Chromatogr A 2001;930(1-2):171-6.

19. Pholphana N, Rangkadilok N, Thongnest S, Ruchirawat S, Ruchirawat M, Satayavivad J. Determination and variation of three active diterpenoids in Andrographis paniculata (Burm.f.) Nees. Phytochem Anal 2004;15(6):365-71.

20. Burgos RA, Caballero EE, Sánchez NS, Schroeder RA, Wikman GK, Hancke JL. Testicular toxicity assessment of Andrographis paniculata dried extract in rats. J Ethnopharmacol 1997;58(3):219-24.

21. Ragasa CY, de los Santos A, Rideout JA. An antimicrobial and cytotoxic labdane diterpene from Andrographis paniculata. ACGC Chem Res Commun 2008;22:44-8.

22. Tan MC, Oyong GG, Shen CC, Ragasa CY. Chemical constituents of Andrographis paniculata (Burm.f.) Nees. Int J Pharmacogn Phytochem Res 2016;8:1398-402.

23. Tan MC, Oyong GG, Shen CC, Ragasa CY. Secondary metabolites from Andrographis paniculata (Burm.f.) Nees. Der Pharm Lett 2016;8:157-60.

24. Tan MC, Oyong GG, Shen CC, Ragasa CY. Chemical composition of Andrographis paniculata (Burm.f.) Nees. Res J Pharm Biol Chem Sci 2016;7:2405-8.

25. Freshney RI. Culture of Animal Cells: A Manual of Basic Techniques. New York, USA: Wiley-Liss Inc.; 2000.

26. Riss TL, Moravec RA. Use of multiple assay endpoints to investigate the effects of incubation time, dose of toxin, and plating density in cell-based cytotoxicity assays. Assay Drug Dev Technol 2004;2:51-62.

27. Geran RI, Greenberg NH, McDonald MM, Schumacher AM, Abbott BJ. Protocols for screening chemical agents and natural products against animal tumour and other biological systems. Cancer Chemother Rep 1972;3:17-9.

28. Jacinto SD, Chun EA, Montuno AS, Espineli DL, Ragasa CY. Cytotoxic cardenolide and sterols from Calatropis gigantea. Nat Prod Commun 2011;6:803-6.

29. Makizumi R, Yang WL, Owen RP, Sharma RR, Ravikumar TS. Alteration of drug sensitivity in human colon cancer cells after exposure to heat: Implications for liver metastatis therapy using RFA and chemotherapy. Int J Clin Exp Med 2008;1:117-29.

30. Ravizza R, Gariboldi MB, Passarelli L, Monti E. Role of the p53/p21 system in the response of human colon carcinoma cells to Doxorubicin. BMC Cancer 2004;4:92.

31. Chao HP, Kuo CD, Chiu JH, Fu SL. Andrographolide exhibits antiinvasive activity against colon cancer cells via inhibition of MMP2 activity. Planta Med 2010;16:1827-33.

32. Sukardiman H, Widyawaruyanti A, Sismindari, Zaini NC. Apoptosis inducing effect of andrographolide on TD-47 human breast cancer cell line. Afr J Tradit Complement Altern Med 2007;4(3):345-51.

33. Li J, Zhang C, Jiang H, Cheng J. Andrographolide inhibits hypoxiainducible factor-1 through phosphatidylinositol 3-kinase/AKT pathway and suppresses breast cancer growth. Oncotargets Ther 2015;8:427-35.

34. Banerjee M, Chattopadhyay S, Choudhuri T, Bera R, Kumar S, Chakraborty B, et al. Cytotoxicity and cell cycle arrest induced by andrographolide lead to programmed cell death of MDA-MB-231 breast cancer cell line. J Biomed Sci 2016;23:40.

35. Chao CY, Li CK, Hsu YT, Lu CY, Liu KL, Li CC, et al. Induction of heme oxygenase-1 and inhibition of TPA-induced matrix metalloproteinase-9 expression by andrographolide in MCF-7 human breast cancer cells. Carcinogenesis 2013;34:1843-51

36. Lin HH, Shi MD, Tseng HC, Chen JH. Andrographolide sensitizes the cytotoxicity of human colorectal carcinoma cells toward cisplatin via enhancing apoptosis pathways in vitro and in vivo. Toxicol Sci 2014;139:108-20.

37. Luo X, Luo W, Lin C, Zhang L, Li Y. Andrographolide inhibits proliferation of human lung cancer cells and the related mechanisms. Int J Clin Exp Med 2014;7(11):4220-5.

38. Lee YC, Lin $\mathrm{HH}$, Hsu CH, Wang CJ, Chiang TA, Chen JH. Inhibitory effects of andrographolide on migration and invasion in human nonsmall cell lung cancer A549 cells via down-regulation of PI3K/Akt signaling pathway. Eur J Pharmacol 2010;632(1-3):23-32.

39. Lim JC, Chan TK, Ng DS, Sagineedu SR, Stanslas J, Wong WS. Andrographolide and its analogues: Versatile bioactive molecules for combating inflammation and cancer. Clin Exp Pharmacol Physiol 2012;39(3):300-10.

40. Roy DN, Mandal S, Sen G, Mukhopadhyay S, Biswas T. 14-Deoxyandrographolide desensitizes hepatocytes to tumour necrosis factor-alpha-induced apoptosis through calcium-dependent tumour necrosis factor receptor superfamily member $1 \mathrm{~A}$ release via the $\mathrm{NO} /$ cGMP pathway. Br J Pharmacol 2010;160:1823-43.

41. Rodríguez-Fernández E, Manzano JL, Alonso A, Almendral MJ, PérezAndrés M, Orfao A, et al. Fluorescent cisplatin analogues and cytotoxic activity. Curr Med Chem 2009;16(32):4314-27.

42. Pfisterer PH, Rollinger JM, Schyschka L, Rudy A, Vollmar AM, Stuppner H. Neoandrographolide from Andrographis paniculata as a potential natural chemosensitizer. Planta Med 2010;76(15):1698-700.

43. Mulukuri NV, Mondal NB, Prasad MR, Renuka S, Ramakrishna K. Isolation of diterpenoid lactones from the leaves of Andrographis paniculata and its anticancer activity. Int J Pharmacogn Phytochem Res 2011:3:39-42.

44. Nanduri S, Nyavanandi VK, Thunuguntla SS, Kasu S, Pallerla MK, Ram PS, et al. Synthesis and structure-activity relationships of andrographolide analogues as novel cytotoxic agents. Bioorg Med Chem Lett 2004;14(18):4711-7. 